\title{
Characterization of xylanase from Streptomyces sp. FA1 and its application for bamboo hydrolysis
}

\author{
Jia-Jia Fu ${ }^{1,2}$, Li-Na Fu ${ }^{1}$, \\ Xiao-Man Zhao ${ }^{1}$, Qun Zhang ${ }^{1}$, \\ Hong-Bo Wang ${ }^{1}$, Wei-Dong Gao ${ }^{1}$
}

\author{
${ }^{1}$ Key Laboratory of Science \& Technology of Eco-textiles Ministry of Education, Jiangnan University,Wuxi, 214122, \\ China \\ e-mail: kathyfjj@126.com,fulinarena317@163.com,wxzhxm09@163.com, shouqunzi1234@163.com, \\ wxwanghb@163.com,gaowd@163.com \\ ${ }^{2}$ National Engineering Laboratory for Modern Silk ,Soochow University, Suzhou, 215123, P.R. China \\ e-mail: kathyfjj@126.com
}

\begin{abstract}
Native cellulose can be disintegrated into substructures with nano-size dimension through electronspinning. Typically, the most common source material available for cellulose nano-fiber production is wood. More attempts are employed to find new suitable resources to produce nano-cellulose at present. Bamboo boasts the abundant resource in China and possesses fast-growing, anti-bacterial, anti-UV, aroma absorbance properties as well as superior physical and mechanical characters. Cellulose is the main constituent in bamboo, which shows great potential to be the ideal source for producing cellulose nano-fiber. Traditional method for bamboo cellulose extraction needs the use of high concentrated alkaline. Such process causes severe environment problems. Therefore, study on alternative green technologies is inevitable. In this work, self-produced xylanase was applied to hydrolyze bamboo noncellulosic substances. Results indicated that such xylanase from Streptomyces sp. FA1 isolated from bamboo retting system showed broad $\mathrm{pH}$ range for xylan hydrolysis, which presented activity of $180 \mathrm{U} / \mathrm{mL}$ and $270 \mathrm{U} / \mathrm{mL}$ under preferred $\mathrm{pH} 5.5$ and $\mathrm{pH} 7$, respectively. Three pretreatment methods (including high temperature, ultrasonic generator and supersonic cleaner) were employed to enhance the bamboo processing, among which, xylanase hydrolysis on high temperature pretreated $\left(120^{\circ} \mathrm{C}, 60 \mathrm{~min}\right)$ bamboo showed the most obvious effect. Thermogravimetric test represented that the weight loss of xylanase hydrolysis on high-temperature pretreated sample was higher than that of original sample, which might be attributed to the decomposition of hemi-cellulose and part of cellulose. This study establishes a base for future studies to develop enzymatic hydrolysis of bamboo noncellulosic materials, making them suitable for cellulose nano-fiber producing.
\end{abstract}

Keywords: Bamboo, xylanase, hydrolysis, high-temperature pretreatment

\section{INTRODUCTION}

Cellulose is the most widespread biopolymer on earth with a long history in fiber manufacturing [1]. It is categorized as a linear polysaccharide and is normally derived from renewable resources in nature [2]. Cellulose is in great development due to its "green" image mainly focusing on their biocompatibility, biodegradability and regenerative properties, which can be deteriorated at the end of the material's life time without adding any pollution load in the atmosphere. [3] Cellulose can be disintegrated into substructures with nano-size dimension through various effective methods. Electrospinning [4] as well as the newly developed bubble electrospinning $[\underline{5}, \underline{6}]$ is the polymer fiber forming technique to produce micro/nanofibers with an extremely specific high surface area at a sub-cellular scale. Fabrication of ultrathin native cellulose fibers via such techniques has drawn great attention in recent years since more solvents have been explored for cellulose dissolving. Proper solvents are selected in completing the electrospinning process of native cellulose, including LiCl/DMAC(dimethylacetamide), NMMO (N-methylmorpholine-N-oxide), and nonvolatile room temperature ionic liquids (RTIL) [2]. Formation of nanofibers via electrospinning of 
cellulose and cellulose derivatives shows great advantages over naturally emerging nanofibers in the formation of a wide variety of fiber morphologies and sizes, and the ability to functionalize and modify the obtained fibers [7]. The most common source material available for cellulose nano-fiber production is wood. In addition, bast fibers, bacterial cellulose, agricultural residues, as well as tunicates are also possible for obtaining cellulose nano-fiber []. More attempts are employed to find new suitable resources to produce nano-cellulose.

Currently, bamboo is emerging as an alternative crop with multiple uses and benefits. As a type of perennial woody and biodegradable plant, bamboo boasts fastest growing property with the rate of growth up to $1 \mathrm{~m}$ per day, and shows superior physical and mechanical characters as well as its anti-bacterial, anti-UV, aroma absorbance characters [9-13]. Cellulose is the main constituents in bamboo, occupying 45-55\% of the total mass [13]. Therefore, it is meaningful to get the utilization of bamboo to extract cellulose for nano-fiber preparation.

Typical methods for bamboo cellulose extraction are based on chemical ways. Bamboos are processed with boiled concentrated alkaline solutions. Such a processing method causes serious environmental pollution and will lead to a continuous deterioration in our living conditions. Thus, more attentions have been gathered on eco-friendly and sustainable techniques in bamboo processing. The addition of enzymes proves the best alternative to the concentrated caustic soda processing for bamboo cellulose extraction. Since bamboo culm contains up to $20-25 \%$ hemicellulose (mainly xylan) [13], it is advisable to choose xylanase to start the hydrolysis.

Xylanase has been widely applied in food, feed, detergent and paper industries, but its application in hydrolysis of hemicellulose on bamboo is still lacking in research [11]. In our previous work, Streptomyces $s p$. FA1 isolated from bamboo retting system showed the higher xylanase activity. [14] Xylanase (XynA) was purified from the culture medium and heterologously expressed in E. coli. The obtained pure xylanase was applied in this work to investigate its ability on bamboo hydrolysis for cellulose extraction. For the purpose of enhancing bamboo accessibility in turn benefiting xylanase hydrolysis, several pretreatments have been investigated, including high-temperature pretreatment, ultrasonic generator pretreatment and ultrasonic cleaner pretreatment, which are eco-friendly and perform little harm to the bamboo cellulose.

\section{MATERIALS AND METHODS}

\subsection{Materials}

One-year-old Moso bamboo (Phyllostachys) culms, harvested from Jiangxi province, P.R. China, were used in this work. Bamboo epidermis was removed and the remaining air-dried culm was crushed in a hammer mill to collect the fractions passing through a No. 40 mesh sieve but retained on a No. 60 mesh sieve. In order to remove the wax, fat and other impurities, the obtained bamboo powders were extracted by organic solvent prior to further enzymatic processing. $1.5 \mathrm{~g}$ of bamboo powders were wrapped by filter paper and extracted with a 2:1 (v:v) mixture of alcohol and benzyl in the Soxhlet extraction system for 4 to 6 times' recycling. The extracted powders were then boiled and rinsed thoroughly with deionized water, and dried in an oven at $80^{\circ} \mathrm{C}$ until constant weight. The treated powders were stored in a glass jar for subsequent use as the substrates. Xylanase is produced by Streptomyces sp. FA1 isolated from bamboo retting system. It was kindly provided by State Key Laboratory of Food Science and Technology, Jiangnan University. All other chemicals were purchased from China National Pharmaceutical Group Chemical Reagent Co., LTD.

\subsection{Methods}

\subsubsection{Xylanase assay}

Xylanase activity was determined by assaying the liberation of reducing sugar from beechwood xylan according to a modified dinitrosalicylic acid (DNS) method, using xylose solution as a reference [15]. $0.5 \mathrm{~mL}$ of appropriately diluted xylanase was incubated with $1.5 \mathrm{~mL}$ of $1 \%(\mathrm{w} / \mathrm{v})$ beechwood xylan solution (dissolved in $50 \mathrm{mM}$ buffer, optimum $\mathrm{pH}$ ) at the optimum temperature for $30 \mathrm{~min}$, and then the reaction was terminated by the addition of $1.5 \mathrm{~mL}$ of DNS reagent. The mixture was subsequently placed in a boiling bath for $5 \mathrm{~min}$, cooled and diluted with the addition of $21.5 \mathrm{~mL}$ of distilled water. The optical density (OD) value of the mixture was measured by the UV spectrophotometer at the wavelength of $540 \mathrm{~nm}$. One unit (U) of xylanase activity is defined as the amount of enzyme required to liberate $1 \mu \mathrm{mol}$ of xylose per minute from beechwood xylan under optimum conditions. Xylanase was tested under various conditions in order to get the 
optimum temperature and $\mathrm{pH}$ for enzyme activity. The activity of the xylanase was determined over the $\mathrm{pH}$ range 3.5-9.0, at $50{ }^{\circ} \mathrm{C}$, using $50 \mathrm{mM}$ buffer containing sodium acetate $(\mathrm{pH} 3.0-5.5)$, sodium phosphate $(\mathrm{pH}$ 5.5-8.0) or Glycine- $\mathrm{NaOH}$ ( $\mathrm{pH} 8.0-9.0$ ). The optimal temperature for xylanase was determined by assaying the enzyme between 30 and $80{ }^{\circ} \mathrm{C}$, at desired $\mathrm{pH}$ with xylan as the substrate. Enzyme assays were all performed in triplicate and the mean values were reported.

\subsubsection{Determination of xylnase concentration for bamboo hydrolysis}

Bamboo hydrolysis was conducted in $50 \mathrm{~mL}$ Erlenmeyer flasks. $250 \mathrm{mg}$ of bamboo powders were immersed in $25 \mathrm{~mL}$ sodium acetate buffer $(50 \mathrm{mM})$ for acidic processing and sodium phosphate buffer $(50 \mathrm{mM})$ for neutral processing with different xylanase dosages ranging from $5 \mathrm{U}$ to $300 \mathrm{U}$, respectively. The flasks were placed in the shaker at $50{ }^{\circ} \mathrm{C}$. At each sampling time, $1.0 \mathrm{~mL}$ of reaction liquor was pipetted and centrifuged at $10,000 \mathrm{rpm}$ for $5 \mathrm{~min}$ to get the supernatant and stored at $-20^{\circ} \mathrm{C}$. Optimal parameters of xylanase hydrolysis were determined by measuring the OD value of the reaction supernatant through DNS method.

\subsubsection{Pretreatments for enhancing bamboo hydrolysis by xylanase}

Three pretreatment processes (including high temperature, ultrasonic generator and supersonic cleaner) were involved to check the possibility to enhance the xylanase hydrolysis performance on bamboo. Hightemperature pretreatment was performed in high pressure reactor at $120{ }^{\circ} \mathrm{C}$ for $15 \mathrm{~min}$. Ultrasonic generator treatment was conducted at $1200 \mathrm{~W}$ and $25 \mathrm{HZ}$ for $30 \mathrm{~min}$. Ultrasonic cleaner treatment was launched at 380 $\mathrm{W}$ and $50{ }^{\circ} \mathrm{C}$ for $30 \mathrm{~min} .250 \mathrm{mg}$ of pretreated bamboo powders were placed in $25 \mathrm{~mL}$ Erlenmeyer flasks with $10 \mathrm{~mL}$ deionized water containing $120 \mathrm{U}$ xylanase. The mixture was incubated in the shaker at $50{ }^{\circ} \mathrm{C}$ for 24 hours. The reducing sugar yield was determined by measuring the OD value of the reaction liquid through DNS method. For a better understanding of high-temperature pretreatment effect on xylanase hydrolysis of bamboo, the pretreating time was further investigated here. Bamboo powders were immersed in the distilled water and incubated in high pressure reactor at $120^{\circ} \mathrm{C}$ for $0 \mathrm{~min}, 15 \mathrm{~min}, 60 \mathrm{~min}$ and $90 \mathrm{~min}$, respectively. The high temperature pretreated bamboo powders were subsequently hydrolyzed by xylanase with the dosage of $120 \mathrm{U}$ in a total reaction volume of $25 \mathrm{~mL}$. The mixture was incubated in the shaker at $50{ }^{\circ} \mathrm{C}$ for 24 hours. Samples were taken at appropriate time and reducing sugar yield was tested to optimize the time factor for high temperature pretreatment.

All of the experiments related with enzymes in subsection 2.2.2 and 2.2.3 were done in duplicate and a control was performed with an equivalent amount of the enzyme inactivated at $100^{\circ} \mathrm{C}$ for $15 \mathrm{~min}$. The final data were shown with the subtraction of the control.

\subsubsection{Thermogravimetric measurement}

Thermogravimetric experiments were carried out on thermogravimetric analyzer from Mettler Toledo international trading co., Ltd. $2 \mathrm{mg}$ of bamboo sample was needed. The sample was kept at $35^{\circ} \mathrm{C}$ for $1 \mathrm{~min}$ for thermal balance. Then the temperature was increased to $850{ }^{\circ} \mathrm{C}$. High purity nitrogen was used as the carrier gas during the processing. The volume flow of $\mathrm{N}_{2}$ was $20 \mathrm{~mL} / \mathrm{min}[16]$.

\section{RESULTS AND DISCUSSION}

\subsection{Specialties of xylanase}

As shown in Figure 1, xylanase produced by Streptomyces sp. FA1 from bamboo retting system can be appropriately used at $\mathrm{pH} 5.5-7.5$ and $50-60^{\circ} \mathrm{C}$ since the optical density (OD) value of the reaction liquid from beechwood xylan hydrolysis by xylanase was higher under this condition. It is well known that the reducing sugar can react with 3,5-Dinitrosalicylic acid in DNS reagents to form 3-amino-5-nitrosalicylic acid which absorbs light strongly at $540 \mathrm{~nm}$. Thus, the higher OD value detected in the reaction liquid represents the higher yield of the reducing sugar from the xylan by xylanase hydrolysis. The results indicated that our selfproduced xylanase had stable and higher activity in both acidic and neutral environments. Xylanase activity reached $180 \mathrm{U} / \mathrm{mL}$ and $270 \mathrm{U} / \mathrm{mL}$ under the preferred condition of pH 5.5 and $\mathrm{pH} 7$, respectively, at $50^{\circ} \mathrm{C}$. 

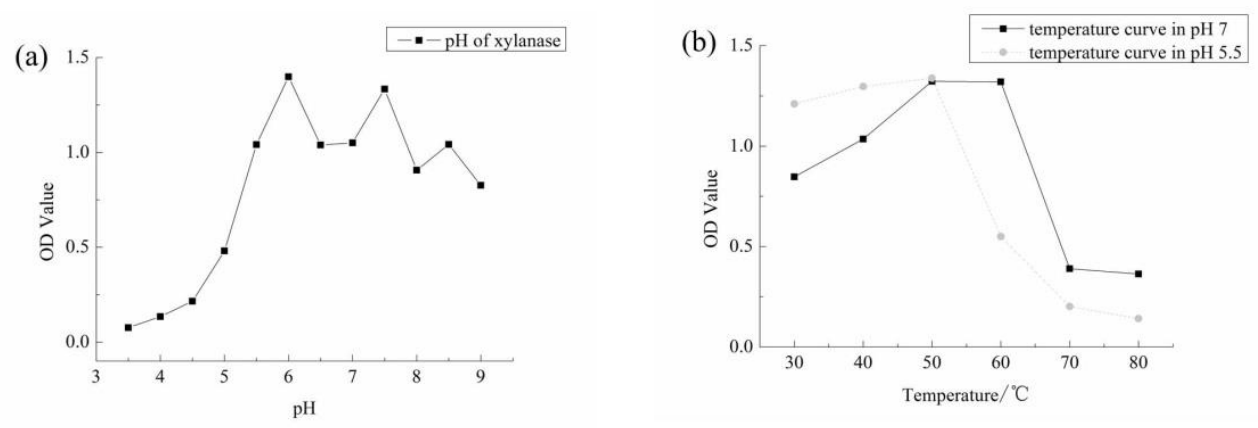

Figure 1: Effect of $\mathrm{pH}$ and temperature on xylanase activity: (a). Optimal $\mathrm{pH}$ of xylnase. Assays were carried at $50^{\circ} \mathrm{C}$ for $30 \mathrm{~min}$ in buffers ranging in $\mathrm{pH}$ from 3.5 to 9.0. (b). Optimal temperature of xylnase. Activity was measured in $50 \mathrm{mM}$ buffer ( $\mathrm{pH} 5.5$ and $\mathrm{pH} 7$ ) at temperature ranges from 30 to $80^{\circ} \mathrm{C}$ for $30 \mathrm{~min}$.

\subsection{Optimization of xylanase concentration for bamboo hydrolysis}

In order to further improve bamboo hydrolysis, the optimization of xylanase dosage was investigated. The results of xylanase hydrolysis on bamboo under neutral condition $\left(\mathrm{pH} 7,50{ }^{\circ} \mathrm{C}\right)$ were shown in Figure 2. It is indicated that the $\mathrm{OD}$ value of reaction liquid, i.e., reducing sugar yield, rose with the increase of xylanase dosage. When the concentration of xylanase was lower than $120 \mathrm{U}$, the hydrolysis was limited within the initial 2 hours since no obvious OD value can be detected. However, with the increase of reaction time, the reducing sugar yield rose since the OD value increased dramatically after 4 hours. When the concentration of xylanase was higher than $120 \mathrm{U}$, bamboo can be hydrolysis immediately based on the observation of the continuous increase of OD value during the initial reaction time. The OD value increased with the incre ase of xylanase concentration, indicating the reducing sugar yield increased as well. However, when the concentration of xylanase reached $300 \mathrm{U}$, the sugar yield showed slight increase compared with the hydrolysis by $250 \mathrm{U}$ xylanse. As can be seen in Figure 2, the reducing sugar showed the highest yield after 12 hours' incubation with the enzyme dosage of $250 \mathrm{U}$. However, such dosage was twice more than $120 \mathrm{U}$ and its reducing sugar didn't reach the equal effect on yield. Thus, $120 \mathrm{U}$ was recommended as the suitable enzyme dosage due to the perspective of energy saving. Unlike the neutral system, bamboo hydrolysis launched under acidic environment $\left(\mathrm{pH} 5.5,50^{\circ} \mathrm{C}\right)$ showed almost no effect since no obvious OD value can be detected from the processing liquid along with the time (data were not shown here).

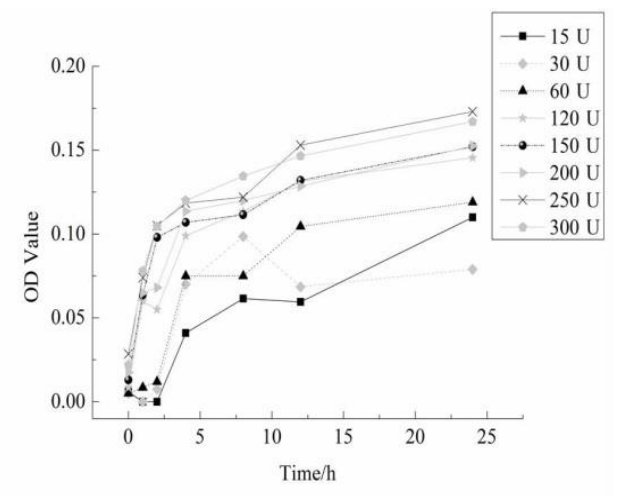

Figure 2: Reducing sugar yield during the enzyme hydrolys is with different xylanase concentration: Hydrolys is was carried out at $50^{\circ} \mathrm{C}$ and $\mathrm{pH} 7$

\subsection{Influence of different pretreatments on xylanase hydrolysis of bamboo}

Results from xylanase hydrolysis of bamboo with different pretreatments were shown in Figure 3, where (a) represented that the hydrolysis was carried out at $\mathrm{pH} 7$ and $50{ }^{\circ} \mathrm{C}$; (b) represented the hydrolysis was carried out at $\mathrm{pH} 5.5$ and $50{ }^{\circ} \mathrm{C}$. In general, compared with untreated bamboo, pretreated samples experienced the increase of reducing sugar yield under the condition of $\mathrm{pH} 7$, especially for the high-temperature pretreated samples. After 12 hours' hydrolysis, the OD value of reaction liquid by xylanase hydrolysis of high- 
temperature pretreated bamboo reached 0.18 , which was nearly 2.25 times higher than that of untreated bamboo and twice of ultrasonic generator and ultrasonic cleaner pretreated bamboo. A reasonable explanation was that high-temperature pretreatment loosened the structure of bamboo and enhanced the possibility for enzyme penetrating into bamboo, thus more available hemicellulose could be exposed to xylanase and in turn strengthening the hydrolysis effect [17]. Meanwhile, the OD value of ultrasonic generator and ultrasonic cleaner pretreated bamboo was slightly above that of un-pretreated bamboo in acidic xylanase hydrolysis system of $\mathrm{pH} 5.5$ at $50^{\circ} \mathrm{C}$. High-temperature pretreated bamboo showed highest reducing sugar yield in both neutral ( $\mathrm{pH} 7)$ and acidic ( $\mathrm{pH}$ 5) environments under the same xylanase treating condition. Thus, high-temperature pretreatment is the ideal method for intensifying xylanase hydrolysis on bamboo. Different high-temperature treating times were studied to find the proper way to perform the pretreatment. As can be seen in Figure 4(a), for the neutral system, xylanase hydrolysis of bamboo with high-temperature pretreatment showed apparently higher reducing sugar yield than that without high-temperature pretreatment. The OD value presented little difference between high-temperature pretreatment for 60 min and 90 min, although the former OD value was slightly lower than the latter one. In other words, the reducing sugar yield from $60 \mathrm{~min}$ high-temperature pretreated samples didn't appear much difference from that of $90 \mathrm{~min}$ pretreated samples. Therefore, it is not necessary to prolong the pretreatment time to $90 \mathrm{~min}$. The similar trend can be observed in the acidic system (shown in Figure 4(b)).
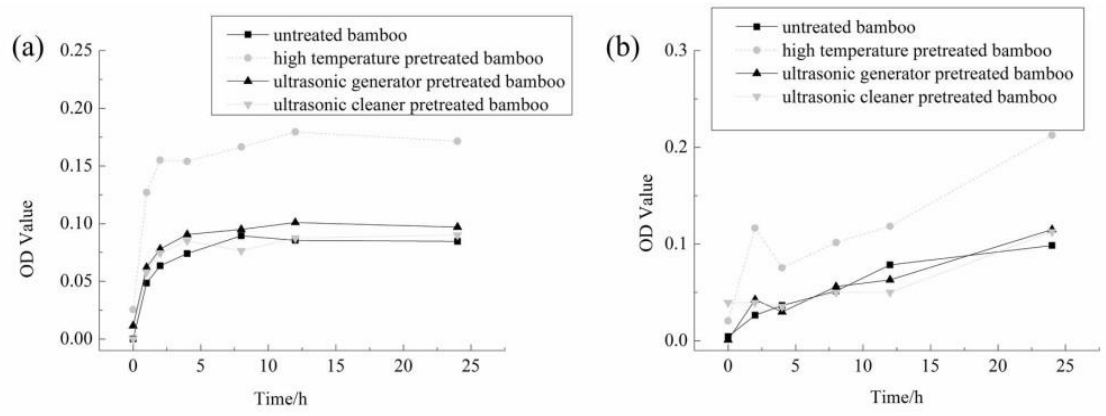

Figure 3: OD Value of enzymatic hydrolysis with different pretreatment processing: (a). the neutral system $\left(\mathrm{pH} 7,50^{\circ} \mathrm{C}\right)$, (b). the acidic system $\left(\mathrm{pH} 5.5,50^{\circ} \mathrm{C}\right)$
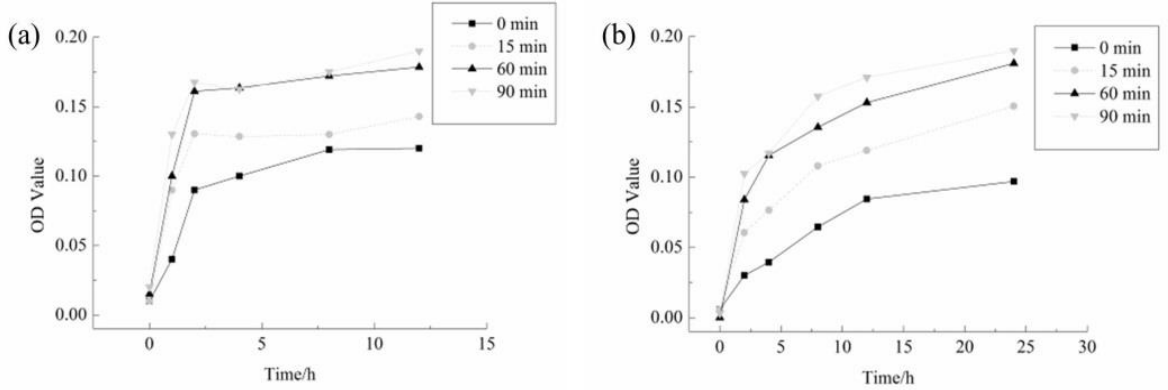

Figure 4: OD value of enzymatic hydrolys is with different processing time: (a). the neutral system ( $\left.\mathrm{pH} 7,50^{\circ} \mathrm{C}\right),(\mathrm{b})$. the acidic system $\left(\mathrm{pH} 5.5,50^{\circ} \mathrm{C}\right)$

\subsection{Thermogravimetric analysis of bamboo}

Bamboos mainly consist of cellulose, hemicellulose, and lignin with little content of pectin, waxes, and water soluble substances. Among them, cellulose plays an important role in physical properties of natural fibers and functions predominance role in their thermal degradation [18]. Figure 5 showed the weight loss of thermal decomposition (a) and differential mass loss thermogram (b) of original bamboo and treated bamboo. As can be seen from the chart, the devolatilization was the main cause to lead the weight loss at about $120{ }^{\circ} \mathrm{C}$, 
approximately $7 \%$ for original bamboo and $9.63 \%$ for xylanase hydrolyzed high-temperature pretreated bamboo). For original bamboo, the pyrolysis of bamboo initiated at approximately $210{ }^{\circ} \mathrm{C}$, then the reaction rate increased linearly and sharply to the peak at approximately $350{ }^{\circ} \mathrm{C}$. The weight losses occurring between $200{ }^{\circ} \mathrm{C}$ and $360{ }^{\circ} \mathrm{C}$ were due to the decomposition of hemicellulose and the breakage of glycosidic bonds. Beyond the temperature $370{ }^{\circ} \mathrm{C}$, the TG and DTG curves leveled off, which revealed the slower decomposition dominated by the lignin. Losses between $360{ }^{\circ} \mathrm{C}$ and $420{ }^{\circ} \mathrm{C}$ were assigned to decomposition of cellulose, and weight losses exceeding $420{ }^{\circ} \mathrm{C}$ were due to decarboxylation reactions to form aldehydes, ketones, esters and then carbon formation $[\underline{19}, \underline{20}]$. It is obvious that the weight loss of xylanase hydrolysis on high-temperature pretreated bamboo is higher than that of original bamboo. The loss of hemi-cellulose and part of cellulose may lead to greater weight loss $[21,22]$.

(a)

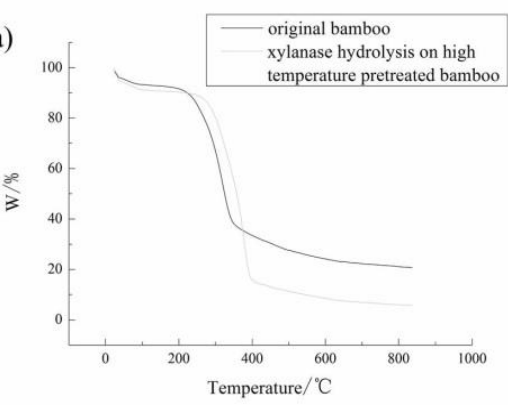

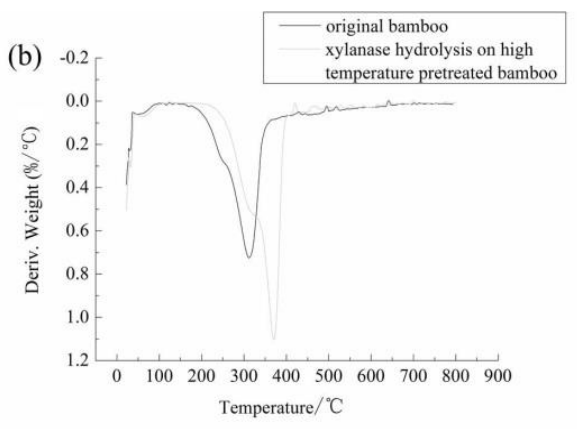

Figure 5: TG and DTG curves of bamboo with different processes: (a). the loss of weight of thermal decomposition (TG), (b). differential mass loss thermogram (DTG)

\section{CONCLUSIONS}

We have investigated the properties of xylanase from Streptomyces sp. FA1 and its performance on bamboo hydrolysis. It is found that xylanase has a wide range of $\mathrm{pH}$, which favors bamboo processing. In three different pretreatment methods, high-temperature pretreatment was effective on enhancing xylanase hydrolysis of bamboo. The optimal processing parameters are $120^{\circ} \mathrm{C}$ and $60 \mathrm{~min}$.

Future work may focus on shortening the high-temperature pretreatment time to achieve the better effect with reduced energy consumption.

\section{ACKNOWLEDGMENTS}

This work is supported by Opening Project of National Engineering Laboratory for Modern Silk (Grant No. KJS1312); the National Natural Science Foundation of China (Grant No. 31201134 and No. 31470509); the Jiangsu Provincial Natural Science Foundation of China (Grant No.BK2012112) and the Industry-academic Joint Technological Prospective Fund Project of Jiangsu Province (Grant No.BY2013015-24).

\section{BIBLIOGRAPHY}

[1] CUCUlO, J.A., AMINUDDIN, N., FREY, M.W., "Solvent spun cellulose fibers”, In: Structure Formation in Polymeric Fibers"; Salem, D. R., Ed., Hanser Publishers, Munich, pp. 296- 328, 2000.

[2] XU, S.S., ZHANG, J., HE, A.H., et al., "Electrospinning of native cellulose from nonvolatile solvent system”, Polymer. v. 49, n. 12, pp. 2911-2917, 2008.

[3] NISHIO, Y., "Material functionalization of cellulose and related polysaccharides via diverse microcompositions”, Advances in Polymer Science, v. 205, pp. 97-151, 2006.

[4] HUANG, Z.M., ZHANG, Y.Z., KOTAKI, M., et al., “A review on polymer nanofibers by electrospinning and their applications in nanocomposites", Composites Science and Technology, v. 63, n. 15, pp. 2223-2253, 2003.

[5] HE, J.H., KONG, H.Y., YANG, R.R., et al., "Review on fiber morphology obtained by bubble electrospinning and blown bubble spinning", Thermal science, v. 16, n. 5, pp. 1263-1279, 2012.

[6] DOU, H., HE, J.H., "Nanoparticles fabricated by the bubble electrospinning", Thermal science, v. 16, n. 
5, pp. 1562-1563, 2012.

[7] MARGARET, W.F., "Electrospinning Cellulose and Cellulose Derivatives", Polymer Reviews, v. 48, n. 2, pp. 378-391, 2008

[8] ADRIANA, N.F., DENIS, M.P., DAN, D. "Some aspects concerning the isolation of cellulose micro- and nano-fibers". UPB Scientific Bulletin,B series: Chemistry and material science, v. 73, Iss. 2, pp. 133-152, 2011.

[9] FU, J.J., YANG, X.X., YU, C.W., "Preliminary Research on Bamboo Degumming by Xylanase”, Biocatalysis and Biotransformation, v. 26, n. 5, pp. 450-454, 2008.

[10] FU, J.J., HENRY M., JOAO V. de C.J., et al., "Changes in the bacterial community structure and diversity during bamboo retting”, Biotechnology Journal, v. 6, n. 10, pp. 1262-1271, 2011.

[11] FU, J.J., NYANHONGO, G. S., SILVA, C., et al., "Bamboo fibre processing: insights into hemicellulase and cellulase substrate accessibility", Biocatalysis and Biotransformation, v. 30, n. 1, pp. 27-37, 2012.

[12] FU, J.J., ZHANG, X.Q., YU, C.W., et al., "Bioprocessing of Bamboo Materials", Fibres \& Textiles in Eastern Europe, v. 20, n. 1, pp. 13-19, 2012.

[13] FU, J.J., LI, X.Q., CAVACO-PAULO, A., et al., "Bio-processing on bamboo fiber extraction for textile application: a mini review”, Biocatalysis and Biotransformation, v. 30, n. 1, pp. 141-153, 2012.

[14] HE, J., SU, L.Q., SUN, X.J., et al., “A Novel Xylanase from Streptomyces sp. FA1: Purification, Characterization, Identification, and Heterologous Expression”, Biotechnology and Bioprocess Engineering, v. 19, n. 1, pp. 8-17, 2014.

[15] FU, L.N., TAN, M.Y, SHI, R.K., et al., "Insights into high temperature pretreatment on cellulase processing of bamboo", Thermal Science, v. 16, n. 5, pp. 1524-1528, 2012.

[16] SLOPIECKA, K., BARTOCCI, P., FANTOZZI, F., "Thermogravimetric analysis and kinetic study of poplar wood pyrolysis”, Applied Energy, v. 97, pp. 491-497, 2012.

[17] KOBAYASHI, F., TAKE, H., ASADA, C., et al., "Methane production from steam-exploded bamboo", Journal of Bioscience and Bioengineering, v. 97, n. 6, pp. 426-428, 2004.

[18] MONTEIRO, S.N., CALADO, V., MARGEM, F.M., et al., "Thermogravimetric behavior of natural fibers reinforced polymer composites - An overview”, Materials Science \& Engineering A, v. 557, pp. 17-28, 2012.

[19] CALVOA, S., ARIAS, N.P., GIRALDO, O., et al., "Thermal and magnetic behavior of Angustifolia Kunth bamboo fibers covered with Fe3O4 particles", Physica B: Condensed Matter, v. 407, n. 16, pp. $3267-$ $3270,2012$.

[20] ZENG, Y.L., YANG, X.W., YU, H.B., et al., "The delignification effects of white-rot fungal pretreatment on thermal characteristics of moso bamboo", Bioresource Technology, v. 114, pp. 437-442, 2012.

[21] MOHD, T.B.M., BHAT, I.U.H., MOHMOD, A.L., et al., "Thermal and FT-IR Characterization of Gigantochloa levis and Gigantochloa scortechinii Bamboo, a Naturally Occurring Polymeric Composite", Journal of Polymers and the Environment, v. 21, n. 2, pp. 534-544, 2013.

[22] RAJULU, A.V., REDDY, G.R., CHARY, K.N., et al., "Thermogravimetric analysis of Dendrocalamus strictus bamboo fibers", Journal of Bamboo and Rattan, v. 1, n. 3, pp. 247-250, 2002. 